\title{
Biometrical analysis of bovine female reproductive system
}

\author{
G. K. Deb*, S. R. Dey, M. K. Alam, N. R. Sarker, M. M. Rahman, T. N. Nahar, and M. F. H. Miraz \\ Bangladesh Livestock Research Institute, Savar, Dhaka 1341, Bangladesh
}

\begin{abstract}
This study was conducted to investigate basic biometric information on organs of female reproductive system of indigenous cows. Ovaries were grouped on the basis of corpus luteum (CL) and ovarian position in the tract. Visible follicles were counted and graded as small $(<3.00 \mathrm{~mm})$, medium $(3.0$ to $8.0 \mathrm{~mm})$ and large $(>8.0 \mathrm{~mm})$. Oocytes were recovered from all visible follicles and graded into four groups (grade 1 to 4 ). Results showed that the oviduct, horn, body of the uterus and cervix of cow's reproductive system were longer and wider than heifers, respectively. Except length, the width and visible follicle numbers in the ovary did not vary with ovarian position or CL. Weight of left and right ovaries did not differ. Weight of ovary was increased $(\mathrm{P}>0.01)$ in presence of $\mathrm{CL}$. Each ovary possessed $9.65 \pm 5.91$ visible follicles belonging to small $(5.38 \pm 0.37)$, medium $(3.57 \pm 0.23)$ and large $(0.72 \pm 0.07)$ groups. Oocyte recovery rate was $62.16 \pm 1.46 \%$. Among the recovered oocytes $52.01 \pm 1.63 \%$ were belonging to grade 1 and 2 . This study provides baseline on biometry of female reproductive system along with follicular statistics of indigenous cows.
\end{abstract}

(Key words: Corpus luteum, follicle, cumulus-oocyte-complex, grading of oocyte, ovary)

\section{Introduction}

Biometric knowledge on different organs of female reproductive system is essential to perform artificial insemination, pregnancy diagnosis, dealing with the infertility problems, in vivo and in vitro manipulation of folliculogenesis and embryo transfer (Memon, 1996). Moreover, understanding of reproductive processes of the dairy cow and a working knowledge of the anatomy or parts of a cow's reproductive tract may be useful in identifying and correcting many situations leading to poor reproductive efficiency (IRM-1). Bangladesh Livestock Research Institute (BLRI) has taken research programme on ovum pick up based in vitro embryo production (OPU-IVP) for multiplication of high yielding cows since 2011 (Deb et al., 2012). Morphometric knowledge on different organs of female reproductive tract and ovarian follicular statistics are required for application of OPU-IVP technology with traditional cattle breeding programme. In vitro embryo development efficiency is largely affected by oocyte numbers in the culture droplet and their quality assessed by evaluation of oocyte morphology (Deb et al., 2011). The developmental potential of poor quality oocyte is generally very low (Stojkovic et al., 2001). Therefore, basic information on the aspirable oocyte numbers from an ovary of indigenous cow/heifer and its quality is

*Corresponding author: debgk2003@yahoo.com

Bang. J. Livs. Res. Vol. 20 (1 \& 2), 2013: P. 1-7, ISSN 1022-3851 
essential for application of the OPU-IVP technology with traditional cattle breeding programme. However, information on biometry of different organs of the female reproductive systems of indigenous cattle as well as their follicular dynamics is scanty. The abattoir female reproductive systems are commonly used for their biometric evaluation (Rind et al., 1999). Therefore, this study was carried out to provide basic information regarding the biometric information on different organs of female reproductive system and follicular statistics of indigenous cow.

\section{Material and Methods}

Ninety non-gravid reproductive systems were collected from slaughtered indigenous cows (delivered minimum one calf) and heifer (>30 months age) from abattoir located at Mohammodpur, Dhanmondi, Dhaka in physiological saline $(0.9 \%$ sodium chloride supplemented with $100 \mathrm{IU} / \mathrm{ml}$ penicillin, $100 \mathrm{~g} / \mathrm{ml}$ streptomycin sulfate) at $25-30^{\circ} \mathrm{C}$ and transported to the laboratory within 4 to $5 \mathrm{hr}$ of slaughter. All logistics required for biometric measurement has been collected and arranged in the working laboratory before transportation of the reproductive systems.

Examination of the specimens waș carried out under bright light. All measurements were recorded in centimeters/millimeters and all weights in grams. Any reproductive system that showed abnormalities were excluded from the study. All measurements were done according to Gupta et al. (2011).
At the date of collection, all reproductive systems were washed in physiological saline and ovaries were removed at their junction with the ovarian ligament as close to the ovarian tissue. The ovaries were grouped on the basis of corpus luteum (CL) (ovary with rudimentary $\mathrm{CL}$; ovary with active $\mathrm{CL}$ and ovary without $\mathrm{CL}$ ) and ovarian position in the tract (right and left ovaries). The remaining systems were kept in polybags and stored at $-20^{\circ} \mathrm{C}$ for analysis of oviduct, uterus and cervical dimensions. The length of ovary was taken along the excision from the ovarian ligament and the width as the greatest line perpendicular to the length line (Figure 1). The weight of the ovary was measured using an electrical balance. All visible follicles were counted and graded as small $(<3.0 \mathrm{~mm})$, medium $(3.0$ to $8.0 \mathrm{~mm}$ ) and large $(>8.0 \mathrm{~mm})$ based on their diameter (Deb et al., 2011). The oocytes from each ovary were aspirated using $10 \mathrm{ml}$ syringe attached with $21 \mathrm{G}$ needle. The aspirated material was poured onto a $35-\mathrm{mm}$ Petri dish and the number of oocytes per ovary was recorded under a compound microscope at low magnification $(4 \mathrm{x})$. The oocytes were graded into four groups (Figure-2) considering their cumulus cell attachment and cytoplamic appearance (Stojkovic et al., 2001).

At the day of measurement of dimensions of different organs (cervix, uterine body, uterine horns and oviducts), the stored reproductive systems (cow: 21 and heifer: 19) were thawed and the organs were cleaned, adhering tissues were removed and placed on a table in normal position. The 
extended length of oviduct was measured from the top of the fimbriae to the tubal uterine horn junction. The length of uterine horn was measured from the oviduct tubal junction to the bifurcation of the body of the uterus. Before measurement, the uterine horns were dissected free of their ligamentous attachments, and extended their full length for measurement. The width of the uterine horn was measured $3.0 \mathrm{~cm}$ apart from the bifurcation of the body of the uterus (Figure 1b). The length of the uterine body was taken from its bifurcation to the internal os of the cervix. The width of the uterine body was measured in the middle position (Figure 1c). The cervical length was measured as the distance between the external os and internal os (Figure 1e) and the width were recorded just beneath of the first ring (Figure 1d). However, the length and width of vagina and vulva were not included in this study. The reproductive system collected from abattoir lacked their intact vagina and vulva during processing of carcasses. Data were analyzed using ANOVA following principles of completely
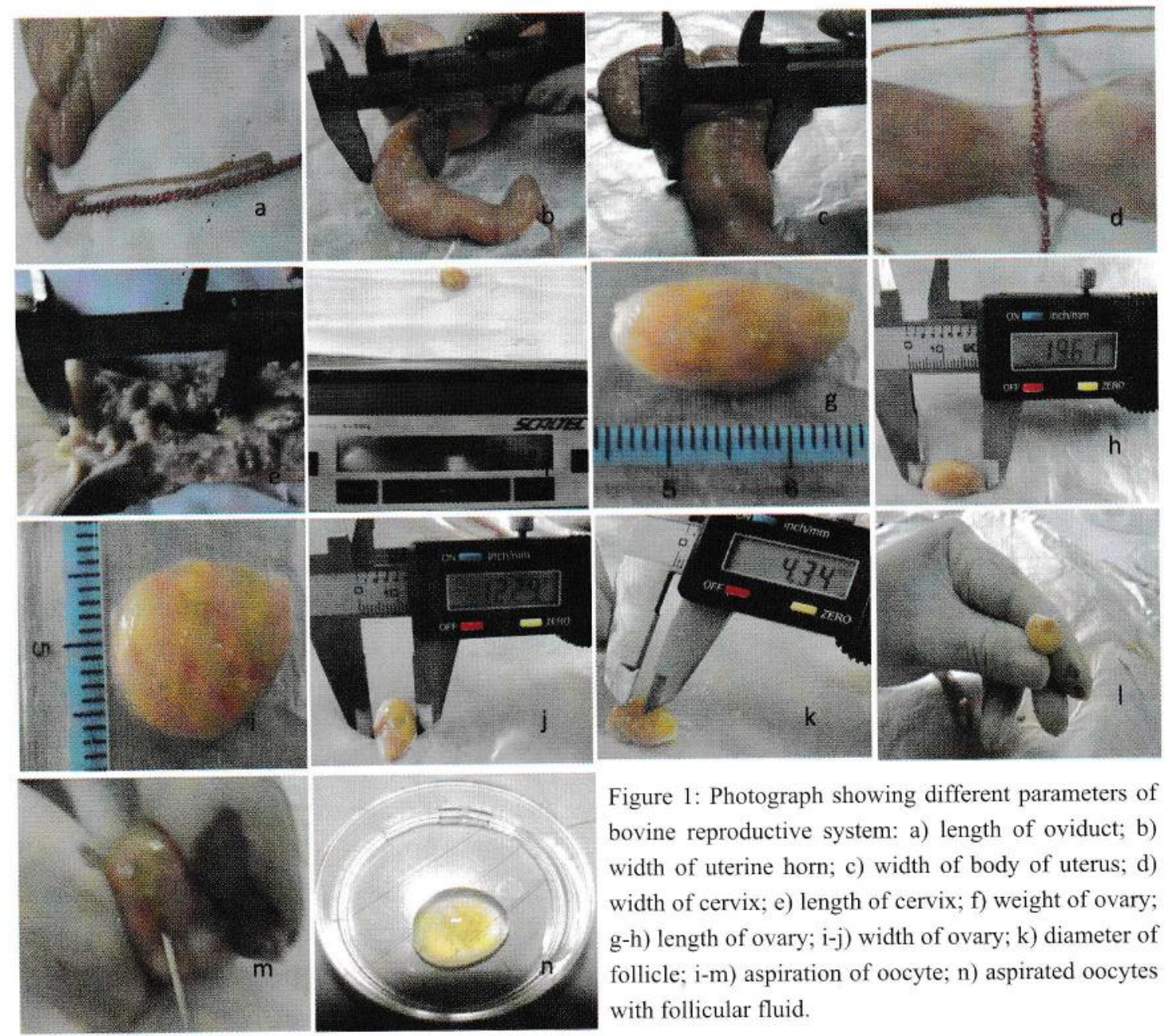

Figure 1: Photograph showing different parameters of bovine reproductive system: a) length of oviduct; b) width of uterine horn; c) width of body of uterus; d) width of cervix; e) length of cervix; f) weight of ovary; g-h) length of ovary; $i-j$ ) width of ovary; $k$ ) diameter of follicle; i-m) aspiration of oocyte; $n$ ) aspirated oocytes with follicular fluid. 


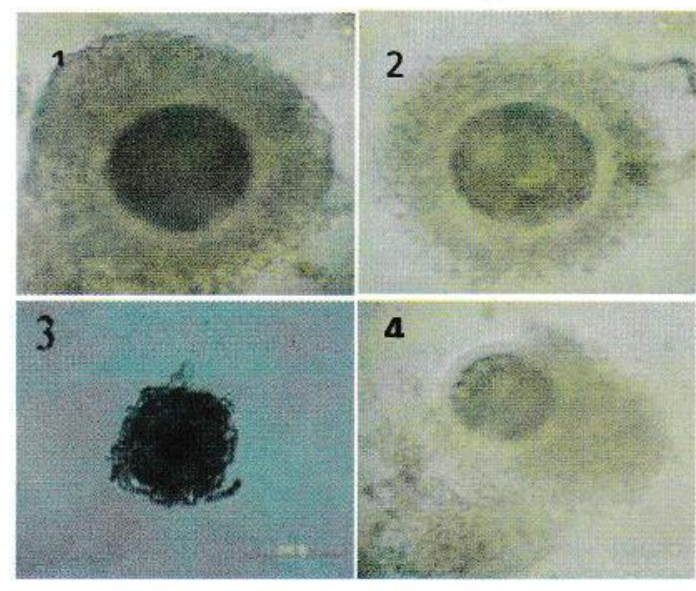

Figure 2: Photograph showing grading system of bovine immature oocytes: (1) Grade 1: homogenous cytoplasm and a complete, compacted, and multilayered cumulus cells (>4); (2) Grade 2= homogeneous cytoplasm with only few areas showing irregular pigmentation and more than three layers of compact cumulus cells; (3) Grade $3=$ heterogeneous cytoplasm with less than 3 layers of cumulus cells and/or small denuded areas and (4) Grade $4=$ heterogeneously pigmentedcytoplasm with complete or mostly denuded areas, expanded cumulus cells.

randomized design experiment to detect significant variations. The Duncan's multiple range test was use to compare mean differences in appropriate cases.

\section{Results and Discussion}

Results showed that the oviduct, horn and body of the uterus and cervix of cows' reproductive system were longer and wider than heifers, respectively (Table 1). The length of oviduct, horn of uterus and cervix were smaller than those reported for adult non-pregnant exotic cows (Hafez, 1993).
The length of uterine body of our indigenous cattle is in range for exotic cattle (Hafez, 1993). The same author showed that the length and width of different organs of female reproductive systems varied with age, breed, parity and plane of nutrition. The smaller length of oviduct, uterine horn and cervix of indigenous cattle may be associated with their small body size and poor nutritional condition.

The length of ovary varied $(\mathrm{P}>0.05)$ with ovarian type (Table 2) and presence or absence of corpus luteum (Table 3 ). The length, width and weight of ovary found in this study were lower than exotic cattle breed (Fact sheet IRM-I, Hafez, 1993). It is not unusual that the small size indigenous cow will possess smaller ovaries than exotic cows. The placement of the ovary in the reproductive system (left or right) or presence/absence of CL did not determine $(\mathrm{P}<0.05)$ the width of ovary. A total of 178 ovaries (88 left and 90 right ovaries) were measured for length, width and weight. Of them, about $24.44 \%$ (22 nos.) of the right ovary posses functional CL and that only $6.82 \%$ left ovary possesses functional $\mathrm{CL}$. The weight of ovary did not differ $(\mathrm{P}<0.05)$ between left and right. However, in presence of $\mathrm{CL}$, the ovarian weight was increased $(\mathrm{P}>0.001)$. Previous report explained that the presence of $\mathrm{CL}$ determined ovarian length and weight. Each ovary possessed $9.65 \pm 5.91$ visible follicles belonging to small (5.38 \pm 0.37$)$, medium (3.57 \pm 0.23$)$ and large $(0.72 \pm 0.07)$ groups, respectively. The numbers of follicles per ovary did not vary with CL and position in the tract. The present 
Table 1. Biometry of different organs of bovine reproductive system

\begin{tabular}{lccc}
\hline \multicolumn{1}{c}{$\begin{array}{c}\text { Organs of the } \\
\text { reproductive system }\end{array}$} & \multicolumn{2}{c}{ Mean \pm SEM (cm) } & \multirow{2}{*}{ Sig. } \\
\cline { 2 - 3 } Oviduct length & $12.21 \pm 0.31$ & $14.86 \pm 0.39$ & $* *$ \\
Length of uterus & $12.17 \pm 0.48$ & $16.55 \pm 0.76$ & $* *$ \\
$\quad$ Horn & $1.90 \pm 0.25$ & $3.05 \pm 0.27$ & $* *$ \\
$\quad$ Body & $1.97 \pm 0.07$ & $2.55 \pm 0.11$ & $* *$ \\
Width of uterus & $2.80 \pm 0.17$ & $3.33 \pm 0.11$ & $* *$ \\
$\quad$ Horn & $4.04 \pm 0.14$ & $4.86 \pm 0.19$ & $* *$ \\
$\quad$ Body & $2.26 \pm 0.10$ & $2.70 \pm 0.14$ & $* *$ \\
Length of cervix & & & \\
Width of cervix & &
\end{tabular}

Table 2. Ovarian biometry according to position of ovary in the female reproductive system

\begin{tabular}{|c|c|c|c|c|}
\hline \multirow[t]{2}{*}{ Parameter } & \multicolumn{3}{|c|}{ Ovary (Mean \pm SEM) } & \multirow[t]{2}{*}{ Sig. } \\
\hline & Left & Right & Total & \\
\hline \multicolumn{5}{|l|}{ Ovary } \\
\hline Length (mm) & $18.45 \pm 0.41$ & $19.55 \pm 0.35$ & $18.99 \pm 0.27$ & $*$ \\
\hline Width (mm) & $12.41 \pm 0.32$ & $14.87 \pm 1.35$ & $13.64 \pm 0.70$ & NS \\
\hline Weight $(\mathrm{g})$ & $1.72 \pm 0.11$ & $1.96 \pm 0.11$ & $1.84 \pm 0.08$ & NS \\
\hline \multicolumn{5}{|c|}{ Number of follicles in each ovary } \\
\hline Small & $5.56 \pm 0.49$ & $5.20 \pm 0.54$ & $5.38 \pm 0.37$ & NS \\
\hline Medium & $3.51 \pm 0.35$ & $3.63 \pm 0.32$ & $3.57 \pm 0.23$ & NS \\
\hline Large & $0.62 \pm 0.09$ & $0.83 \pm 0.10$ & $0.72 \pm 0.07$ & NS \\
\hline Total visible & $9.67 \pm 0.61$ & $9.64 \pm 6.22$ & $9.65 \pm 5.91$ & NS \\
\hline Oocyte recovery rate $(\%)$ & $61.0 \pm 2.08$ & $63.3 \pm 2.04$ & $62.2 \pm 1.46$ & NS \\
\hline \multicolumn{5}{|l|}{ Oocyte quality } \\
\hline Grade 1 & $2.16 \pm 0.15$ & $1.92 \pm 0.15$ & $2.04 \pm 0.11$ & NS \\
\hline Grade 2 & $1.22 \pm 0.11$ & $1.34 \pm 0.11$ & $1.28 \pm 0.80$ & NS \\
\hline Grade 3 & $1.13 \pm 0.11$ & $1.18 \pm 0.13$ & $1.15 \pm 0.08$ & NS \\
\hline \multirow[t]{2}{*}{ Grade 4} & $1.82 \pm 0.16$ & $1.92 \pm 0.14$ & $1.87 \pm 0.10$ & NS \\
\hline & $51.7 \pm 2.17$ & $52.4 \pm 2.45$ & $52.0 \pm 1.63$ & NS \\
\hline
\end{tabular}

* Significant at $5 \%$ level; NS: non-significant

results are inconsistent with Rahman et al., (2003) who reported that the numbers of follicle varies from $4.37 \pm 0.58$ to $6.48 \pm 0.38$ in abattoir ovaries of Bangladesh. They also showed that the follicle number is low in presence of CL. These facts may explain by the numbers of samples used for representation of these parameters. Moreover, the 
age, nutritional condition and other factors of slaughtered animals may be associated with low numbers of follicles in the ovaries. The numbers of follicles according to size (small, medium and large follicle) did not differ with ovarian position and presence or absence of CL. Rahman et al., (2003) showed similar non significant variation in follicle numbers according to size with CL.

Diameters of a follicle determine the development capacity of the oocyte to blastocyst stage in vitro. Oocytes collected from 3 to $8 \mathrm{~mm}$ diameter follicles have higher potential than those collected from small $(<3.0 \mathrm{~mm})$ and large follicles
$(>8.0 \mathrm{~mm})$. Neither ovarian position (left/right) nor presence of CL has effect on follicle numbers in the ovary. Number of oocytes aspirated from an ovary and oocyte recovery rates were independent of ovarian position and presence of CL. About $52.01 \pm 1.63 \%$ of the aspirated oocytes were morphologically good for in vitro maturation, fertilization and culture. This result is in agreement with (Deb et al., 2011). They showed that $49.2 \%$ of the recovered bovine oocytes were good quality (grade $1+$ grade 2).

Table 3. Effect of corpus luteum on ovarian biometry

\begin{tabular}{|c|c|c|c|c|c|}
\hline \multirow{2}{*}{ Parameter } & \multicolumn{4}{|c|}{ Corpusluteum (Mean \pm SEM) } & \multirow[t]{2}{*}{ Sig. } \\
\hline & Rudimentary & Functional & Absence & Total & \\
\hline \multicolumn{6}{|l|}{ Ovary } \\
\hline Length $(\mathrm{mm})$ & $19.46 \pm 0.87$ & $20.23 \pm 0.56$ & $18.58 \pm 0.33$ & $18.99 \pm 0.27$ & $*$ \\
\hline Width (mm) & $14.27 \pm 0.62$ & $14.69 \pm 0.54$ & $13.26 \pm 0.98$ & $13.64 \pm 0.70$ & NS \\
\hline Weight (g) & $2.30^{\mathrm{a}} \pm 0.23$ & $2.53^{\mathrm{a}} \pm 0.28$ & $1.59^{b} \pm 0.06$ & $1.84 \pm 0.08$ & $* *$ \\
\hline \multicolumn{6}{|l|}{ Number of follicle per ovary } \\
\hline Small & $5.11 \pm 0.88$ & $4.65 \pm 0.53$ & $5.60 \pm 0.48$ & $5.38 \pm 0.36$ & NS \\
\hline Medium & $3.22 \pm 0.48$ & $3.52 \pm 0.52$ & $3.64 \pm 0.29$ & $3.57 \pm 0.24$ & NS \\
\hline Large & $0.44 \pm 0.12$ & $0.6 \pm 0.12$ & $0.79 \pm 0.09$ & $0.72 \pm 0.07$ & NS \\
\hline Total visible follicle & $8.72 \pm 0.89$ & $8.77 \pm 0.79$ & $10.02 \pm 0.59$ & $9.65 \pm 0.45$ & NS \\
\hline Oocyte /ovary & $6.00 \pm 0.45$ & $5.56 \pm 0.35$ & $6.63 \pm 0.34$ & $6.34 \pm 0.25$ & NS \\
\hline Oocyte recovery rate $(\%)$ & $65.97 \pm 4.37$ & $63.54 \pm 3.77$ & $61.22 \pm 0.69$ & $62.16 \pm 1.46$ & NS \\
\hline \multicolumn{6}{|l|}{ Oocyte quality } \\
\hline Grade 1 & $1.65 \pm 0.23$ & $1.88 \pm 0.17$ & $2.16 \pm 0.14$ & $2.04 \pm 0.11$ & NS \\
\hline Grade 2 & $1.35 \pm 0.19$ & $0.97 \pm 0.11$ & $1.36 \pm 0.11$ & $1.28 \pm 0.08$ & NS \\
\hline Grade 3 & $1.18 \pm 0.18$ & $1.06 \pm 0.18$ & $1.18 \pm 0.11$ & $1.15 \pm 0.08$ & NS \\
\hline Grade 4 & $1.82 \pm 0.19$ & $1.67 \pm 0.18$ & $1.94 \pm 0.14$ & $1.87 \pm 0.10$ & NS \\
\hline$\%$ cultivable oocyte (Grade $1+2$ & 2) $47.68 \pm 4.23$ & $52.62 \pm 4.42$ & $52.51 \pm 1.91$ & $52.01 \pm 1.63$ & NS \\
\hline
\end{tabular}

* Significant at $5 \%$ level; ${ }^{* *}$ significant at $1 \%$ level; NS: non-significant 


\section{Conclusion}

It is inferred that the baseline information on biometry of different organs of female reproductive system and follicular statistics of indigenous cows developed during this study may be useful for application of ovum pick up and embryo transfer technology.

\section{References}

Deb, G.K., Jong, I. Jin, Kwon, T.H., Choi, B.H., Cho, S.J., Bang, J.I., Dey, S. R, Cho, I.R., and Kong, 1.K. 2011. Improved blastocyst development of single cow OPU-derived presumptive zygotes by group culture with agarose-embedded helper embryos. Reproductive Biology and Endocrinology. 9: 121.

Deb, G.K., Dey, S.R., Alam, M.K., Sarker, N.R., Khondoker, M.A.M.Y, and Rahman, M.M. 2012. Establishment of in vitro embryo production system with slaughterhouse ovaries. Proceedings of the Annual Research Review Workshop heid in Bangladesh Livestock Research Institute, Savar, Dhaka during 22-23 June 2012.

Fact sheet IRM-1. Anatomy of the cow's reproductive tract. Dairy Integrated Reproductive Management. http $/ /$ www.wvu.edu / agexten/forglvst/Dairy/dirml.pdf.

Gupta, M.D., Akter, M.M., Gupta. A.D., and Das, A. 2011. Biometry of Female Genital Organs of Black Bengal Goat. International Journal of Natural Sciences. 1: 12-16.

Hafez, E.S.E. 1993. Anatomy of female reproduction. In: Reproduction in Farm Animals, 6th Edition, Edited by Hafez E.S.E. Lea and Febiger, USA.
Memon, M.A. 1996. Diagnosis of Pregnancy and Infertility by Rectal Palpation: Bovine Obstetrics. DVCS Washington State University, Pullman. pp: 65-68.

Rahman, M.G., Goswami, P.C., Yahia Khondoker, M.A.M., Tareq, K.M.A., and Ali, S.Z. 2003. Collection of bovine cumulusoocyte-complexes(COCs) from slaughterhouse ovaries in Bangladesh. Pakistan Journal of Biological Science. 6: 2054-2057.

Rind, R.; Brohi, M.A, and Bhatti, W.M. 1999. Studies on biometry of ovary during pregnancy in buffaloes.PASF/PVMA AgroLivestock Conf. Lahore, Pakistan. pp: 72-74.

Stojkovic M., Machado, S.A., Stojkovic, P., Zakhartchenko, V., Hutzler, P., Goncalves, P. B., and Wolf, E. 2001. Mitochondrial distribution and adenosine triphosphate content of bovine oocytes before and after in vitro maturation: correlation with morphological criteria and developmental capacity after in vitro fertilization and culture. Biology of Reproduction.64: 904-909. 